\title{
Signé Pombo de Louise Doutreligne: una transposición dramática francesa de la Autobiografía del general Franco de Manuel Vázquez Montalbán
}

\author{
Evelio MiÑANO MARTíNEZ \\ Universitat de València \\ Departament de Filologia Francesa i Italiana \\ Evelio.Minano@uv.es
}

Recibido: 05/09/2013

Aceptado: 16/11/2013

\begin{abstract}
Resumen
Signé Pombo, también titulada Dans la peau de Franco, es una creación dramática francesa de Louise Doutreligne libremente inspirada, como consta en la cubierta de la edición de Moi, Franco, título con el que se ha traducido en francés la Autobiografía del general Franco de Manuel Vázquez Montalbán. En este artículo se estudian las transformaciones creativas a que ha sido sometido el relato de Vázquez Montalbán, atendiendo principalmente a las modificaciones cuantitativas, la reordenación de la materia y el paso de la polifonía narrativa a una polifonía escénica, planteándose si la autora ha procedido a cambios pensando en una recepción lectora o teatral francesa.
\end{abstract}

Palabras clave: Literatura comparada, literatura francesa contemporánea, teatro, historia, dictadura.

Signé Pombo de Louise Doutreligne: une transposition dramatique française

\section{Résumé}

Signé Pombo, intitulée aussi Dans la peau de Franco, est une création dramatique française de Louise Doutreligne librement inspirée, comme il est indiqué sur la couverture de l'édition de Moi, Franco, titre avec lequel l'Autobiografía del general Franco de Manuel Vázquez Montalbán a été traduite en français. Dans cet article nous étudions les transformations créatrices auxquelles a été soumis le récit de Vázquez Montalbán, tenant compte principalement des modifications quantitatives, de la remise en ordre de la matière et du passage de la polyphonie narrative à la polyphonie scénique, en nous demandant si l'auteure a procédé à ces transformations avec l'idée d'envisager une réception lectrice ou théâtrale française.

Mots clés : Littérature comparée, littérature française contemporaine, théâtre, histoire, dictature. 


\title{
Louise Doutreligne's Signé Pombo: a French dramatic transposition of the Manuel Vázquez Montalbán's Autobiografía del general Franco
}

\begin{abstract}
Signé Pombo, also called Dans la peau de Franco, is a French dramatic creation by Louise Doutreligne which has been "freely inspired," as it is stated on the edition cover, by Moi, Franco, the title with which the Autobiografia del general Franco by Manuel Vázquez Montalbán has been translated into French. This paper studies the creative transformations that Vázquez Montalbán's narration has undergone, primarily attending to the quantitative changes, the rearrangement of the subject and the passage from a narrative polyphony to a scenic one. The study will ultimately examine to what extent the author has proceeded to those changes keeping in mind either a reading or a theatrical French reception.
\end{abstract}

Key words: Comparative literature, contemporary French literature, theatre, history, dictatorship.

Sumario: Introducción, 1. Transformaciones cuantitativas y sustituciones, 2. De la temporalidad de la fábula narrativa a la temporalidad de la fábula dramática, 3 . De la polifonía narrativa a la polifonía dramática, 4. Conclusión: liberarse para olvidar.

\section{Referencia normalizada}

Miñano Martínez, E. (2014). "Signé Pombo de Louise Doutreligne: una transposición dramática francesa de la Autobiografia del general Franco de Manuel Vázquez Montalbán”. Thélème. Revista Complutense de Estudios Franceses, Vol. 29, Núm. 1: 141-159. http://dx.doi.org/10.5209/rev_THEL.2014.v29.42951

\section{Introducción}

Louise Doutreligne (Roubaix, 1948) es una escritora que la crítica literaria ha situado en la generación de autoras dramáticas francesas de los años 70 y 80 (Moss, 1987; Sadowska, 1997) ${ }^{1}$. Su obra presenta una sorprendente variedad: ha pasado de un teatro intimista, centrado en los laberintos del deseo (Détruire l'image, 1981), a un teatro de debate sobre problemas acuciantes de la sociedad actual, como ocurre en C'est la faute à Le Corbusier! (2013), que trata de arquitectura y urbanismo desde una perspectiva muy crítica. También ha pasado de universos dramáticos desconcertantes por su tratamiento de los personajes, las voces o el tiempo a otros más fáciles de aprehender, como ocurre con la obra antes citada, que se podría calificar de teatro de ideas. En esa extensa trayectoria de más de treinta títulos, España ha sido en varias ocasiones fuente de inspiración. Y lo ha sido hasta tal punto que la autora ha dado el título genérico de Séductions espagnoles a un

\footnotetext{
${ }^{1}$ Este trabajo se enmarca en el proyecto REMELICE (Réception et Médiation de Littératures et Cultures Étrangères et Comparées) EA 4709, de la Université d'Orléans.
} 
conjunto de siete obras, vinculadas de modo diverso con la cultura española (Miñano, 2010a) ${ }^{2}$.

Signé Pombo (2003), titulada posteriormente Dans la peau de Franco, es la única séduction espagnole que se inspira en una novela española contemporánea: está "librement inspirée du roman de Manuel Vázquez Montalbán Moi, Franco", como reza en la cubierta del libro. Moi, Franco es el título con que Bernard Cohen (1994) ha traducido al francés la imaginaria Autobiografía del general Franco (1982), del escritor catalán ${ }^{3}$. Por lo tanto, el circuito de la comunicación literaria ha dado lugar a dos transducciones, "transmission with transformations" (Doležel, 1986: 29), es decir a dos procesamientos sucesivos del texto que se han materializado en sendas creaciones literarias. La cadena de transducciones que observamos aquí es, pues, un ejemplo del fenómeno apuntado por Doležel (1986: 28): "Literary texts constantly 'transcend' the boundary of isolated speech events and enter into complex chains of transmission" ". Así, desde la novela española hasta la obra dramática francesa ha habido dos transducciones: traducción de la novela española en lengua francesa y transformación de la novela francesa en obra de teatro de la misma lengua; a ello hay que añadir una traducción española de la obra teatral francesa (Martín Bermúdez, 2003), que devuelve esta cadena de transducciones a la lengua original, y una versión más corta e inédita de Signé Pombo de la propia escritora, con el título Le jour où Franco est mort, mon père respirait encore ${ }^{5}$.

En términos acuñados por Gérard Genette, se trata de prácticas hipertextuales consistentes en transformaciones serias o transposiciones (1992: 291), declaradas todas ellas ya que siempre se cita la fuente, desde la novela de Vázquez Montalbán, primer hipotexto ${ }^{6}$, hasta el último hipertexto por ahora inédito. Nuestra investigación se centra en un punto de la cadena de transducciones: el paso de la traducción francesa de la novela a la creación dramática en esa misma lengua. Escapan, pues, a nuestra observación, por los límites de este trabajo, otras prácticas hipertextuales situadas en la cadena: la traducción, ya sea de la novela española o de la obra dramática francesa, y la transformación reciente de Signé Pombo en Le jour où Franco est mort mon père respirait encore. Investigamos fundamentalmente, otra vez en términos de Genette, una transmodalización: "une transformation portant sur ce que l'on appelle, depuis Platon et Aristote, le mode de représentation d'une

\footnotetext{
${ }^{2}$ Teresada (1987), Don Juan d'origine (1991), Carmen la nouvelle (1993), L'Esclave du démon (1995), Signé Pombo (2003), La casa de Bernarda Alba (2008) y La novice et le jésuite (2009).

${ }^{3}$ Estrenada en 2002 en el Théâtre du Lierre y, en traducción española de Santiago Martín Bermúdez, en el teatro García Lorca de Getafe, dentro del VII Festival Madrid Sur, en ambos casos dirigida por Jean-Luc Paliès.

${ }_{5}^{4}$ Subrayado del autor.

${ }^{5}$ Esta información nos ha sido transmitida por la autora.

${ }^{6}$ Cabría, de hecho, preguntarse si discursos, declaraciones o documentos del dictador no constituyen, al menos en parte, otro previo hipotexto de la novela de Vázquez Montalbán.
} 
œuvre de fiction: narratif ou dramatique" (1992: 396), en concreto una dramatización.

La transposición de una novela en una obra teatral trae consigo modificaciones insalvables, que ponen a prueba la inventiva del dramaturgo, como aquí ha ocurrido. En este caso, se ha pasado, además, de una extensa novela, cuya lectura requiere varias horas, a un texto dramático para una representación de aproximadamente una hora y media. Por consiguiente, es de esperar que se hayan producido transformaciones cuantitativas reductoras entre el texto origen y el texto meta (Genette, 1992: 323); pero tampoco hemos de descartar alguna transformación cuantitativa inversa, dado que, como afirma el semiólogo francés, reducción y ampliación no están tan separadas como podría pensarse (1992: 384). Por otra parte, el tiempo de la fábula dramática ha debido necesariamente ser transformado: la novela española diferencia dos sucesiones cronológicas: la que corresponde a la escritura por Pombo de la autobiografía imaginaria, con todo aquello que la contextualiza, y la que corresponde a los hechos rememorados por el dictador y por el propio Pombo, el cual replica a los recuerdos del dictador con los suyos de universitario antifranquista, hijo de republicano represaliado. Nos preguntamos por el modo en que esas continuas analepsis se han transformado en la obra dramática, ya que, como afirma Genette (1992: 397-398), la flexibilidad del relato apenas tiene equivalente en la escena. Asimismo, la polifonía de la novela, en que las voces del dictador y de Pombo se alternan, necesariamente ha debido de tener alguna transformación, por la mera razón de que, en el teatro, por definición, las voces se concretan en personajes o acotaciones.

En ningún caso pensamos que se trate de operaciones mecánicas; antes bien, la transmodalización y transformaciones cuantitativas son creación literaria, aunque solo sea porque, como dice el propio Genette, es raro que esas transposiciones sean inocentes y no afecten de algún modo al sentido (1992: 417). De hecho, convertido en obra de teatro, el relato se sitúa en el universo dramático de Louise Doutreligne respondiendo a algunas de sus coordenadas, como son la dramatización de los actos de lectura y escritura (Miñano, 2009) o la diferenciación entre fábula dramática marco y enmarcada (Miñano, 2010b). También nos preguntamos si la presentación del dictador a un público de lengua francesa ha acarreado tratamientos específicos de su figura, dado que la experiencia de la dictadura franquista de los franceses, aun cuando no sea algo desconocido para ellos, no es comparable a la de aquellos que, como el propio Vázquez Montalbán, la vivieron desde dentro.

En conclusión, estudiamos tres aspectos de una transmodalización creativa: las transformaciones cuantitativas, de la temporalidad y de la polifonía ${ }^{7}$. Se trata en

${ }^{7}$ La dramatización de relatos es una actividad frecuente de la autora, ya sea de fuentes francesas (Conversation sur l'infini des passions, a partir de relatos de Mme de Villedieu, Crébillon-fils y Balzac) ya extranjeras (Vita brevis, a partir de la obra homónima de Jostein Gaarner). Véase sobre este tema el estudio de Keller-Rahbé (2012). 
buena medida de desentrañar ese librement inspiré paratextual que media entre la traducción francesa y la obra de teatro.

\section{Transformaciones cuantitativas y sustituciones}

La traducción francesa ocupa 554 páginas y la obra dramática 53. Es evidente, pues, que la autora ha procedido a una reducción del hipotexto. En ningún caso se trata de una excisión, en la terminología de Genette, esto es de un corte para, simple y llanamente, aligerar el texto resultante. Los hechos, las ideas fundamentales de la novela han sido mantenidos en la obra de teatro: las negociaciones del editor con Pombo para que acepte el proyecto, la biografía del dictador, sus actuaciones fundamentales desde antes de la Guerra Civil hasta su muerte, sus ideas y obsesiones -como su convencimiento de la misión histórica que ha llevado a cabo o la masonería-, los hechos vividos en paralelo por la familia de Pombo y él mismo, todo ello ha sido conservado en la obra teatral. Siguiendo con la terminología de Genette, Louise Doutreligne ha reducido por el procedimiento de la concisión: "abréger un texte sans en supprimer aucune partie thématiquement significative, mais en le récrivant dans un style plus concis, et donc en produisant à de nouveaux frais un nouveau texte, qui peut à la limite ne plus conserver un mot du texte original" (1992: 332). Ciertamente, se han suprimido partes, como, a modo de ejemplo, detalles de la infancia, de la formación del dictador en la Academia Militar de Toledo o de su participación en las guerras coloniales de África; en todo caso, se trata de supresiones que no afectan a ninguna parte significativa de la obra. Louise Doutreligne ha sido ante todo una lectora perspicaz que ha sabido encontrar lo esencial de la obra y abreviarlo; y eso lo comprobamos desde el principio observando cómo las páginas del capítulo inicial de la novela en que Pombo cuenta su situación personal en el presente -su fracaso matrimonial, los problemas con su hija drogadicta y su desorientación vital- se han abreviado en unas pocas líneas de la primera secuencia dramática.

Lo sorprendente es que, aunque la autora abrevie, en numerosas ocasiones tiene un escrupuloso respeto por el texto origen, que traslada tal cual o con leves modificaciones gramaticales, contrariamente al caso límite señalado por Genette en el procedimiento de la concisión, en que no se conserva ninguna palabra del original (1992: 332). Se trata de frases cortas, repetidas, ya sean expresiones emblemáticas -"le garrot et les journaux" (Vázquez, 2005: 231; Doutreligne, 2003: 34)-, o palabras pronunciadas por la madre del dictador: "Paquito, mon fils, tu as des yeux qui intimident" (Vázquez, 2005: 29, 33; Doutreligne, 2003: 19). Pero 
fragmentos más extensos, pronunciados por Franco o por Pombo, han sido objeto también de ese respeto, a lo sumo con supresiones o modificaciones mínimas ${ }^{8}$ :

On naît serein, ce sont les aléas et les coutumes de l'existence qui modifient notre caractère. Chez moi, la sérénité congénitale a été entretenue par le service des armes et par la pratique du sport en temps de paix. Le sport est la continuation de la guerre, et je m'y suis consacré toute ma vie, ce qui m'a valu ces jambes musclées dont mes tailleurs et Vicentón ont fait si souvent l'éloge (Vázquez, 2005: 475).

FRANCO (en confidence): Nous naissons sereins, ce sont les aléas et les coutumes de l'existence qui modifient notre caractère. Chez moi, la sérénité congénitale a été entretenue par le service des armes et par la pratique du sport. Le sport est la continuation de la guerre, et je m'y suis consacré toute ma vie, ce qui m'a valu ces jambes musclées dont mes tailleurs ont fait si souvent l'éloge (Doutreligne, 2003: 45).

Algunos fragmentos separados entre sí en el hipotexto han sido respetados, pero unidos en la creación dramática. Este fenómeno pone de manifiesto que la autora dramática ha asimilado esta obra con tal profundidad que ha vinculado en su mente fragmentos separados en ella, apoyándose en sus puntos de confluencia. Así, el final de la secuencia 6 (Doutreligne, 2003: 36-37) retoma, con pocos cambios, las palabras de Pombo cuando contradice en la novela la satisfacción expresada por el dictador el día del desfile de la Victoria (Vázquez, 2005: 300-301). La última frase de ese fragmento, idéntica en ambas obras -"Je raconterai seulement ce que j'ai vécu, Excellence"- es seguida en la novela por el recuerdo de Pombo niño cuando le hicieron asistir al juicio de su padre para intentar conmover al tribunal, escena de la que recuerda obsesivamente el color kaki de los uniformes. Sin embargo, en la obra dramática esa frase enlaza con otro color, el negro simbólico de aquellos años, retomando con escasas modificaciones un fragmento que aparece varias páginas después en la novela:

Je raconterai seulement ce que j'ai vécu, Excellence [...] Si je devais vous donner une impression tangible de cette époque, je citerais l'obscurité. Il me semble même que la nuit tombait plus tôt alors [...] (Vázquez, 2005: 301, 316).

${ }^{8}$ Sin ser exhaustivos, podemos indicar otros pasajes de la obra que han sido igualmente respetados. En el caso de Franco: la explicación de la expresión le garrot et les journaux (Vázquez, 2005: 195; Doutreligne, 2003: 34), la descripción de Pasionaria (Vázquez, 2005: 195; Doutreligne, 2003: 26), la negación de que la voluntad de poder lo haya movido (Vázquez, 2005: 451; Doutreligne, 2003: 33), su supuesta superación de la propaganda antiespañola relacionada con crímenes de la Guerra Civil (Vázquez, 2005: 242; Doutreligne, 2003: 34), el rechazo de responsabilidad en el bombardeo de Guernica (Vázquez, 2005: 243; Doutreligne, 2003: 35), sus gustos personales y el papel que le ha otorgado la Providencia (Vázquez, 2005: 451; Doutreligne, 2003: 46), el proceso de Burgos (Vázquez, 2005: 503; Doutreligne, 2003: 47), etc. En el caso de Pombo: las críticas al primer desfile de la Victoria tras la Guerra Civil (Vázquez, 2005: 300-301; Doutreligne, 2003: 36-37) y la exposición de las razones por las que se hizo antifranquista (Vázquez, 2005: 11; Doutreligne, 2003: 45). 
Je raconterai seulement ce que j'ai vécu, Excellence et si je devais donner une image tangible de cette époque, je citerai l'obscurité... il me semble même que la nuit tombait plus tôt... oui, l'obscurité... (Doutreligne, 2003: 37).

Louise Doutreligne enlaza, pues, fragmentos de la novela, trasladados con escasas modificaciones, reunidos o no con otros de los que están separados, y abrevia el resto del relato. Este hecho pone de manifiesto una característica esencial de esta transposición: el paso de la novela al teatro no ha impedido un respeto por el estilo del autor, sobre todo en los fragmentos que se han trasladado sin apenas modificaciones. De este modo, Louise Doutreligne está poniendo de relieve el acierto de la escritura de su fuente, con un respeto propio de las citas, que es una invitación por medio del teatro a leer el libro en que se ha inspirado.

Sin embargo no todo ha sido reducir. La autora ha ampliado, al menos en proporción dentro de la reducción general de 554 a 53 páginas, algunas partes de la obra, lo cual se relaciona sin duda con sus preocupaciones y orientaciones personales. La novela solo alude dos veces a la tétrica costumbre de darle a alguien un paseo; lo hace en concreto cuando Pombo recuerda ese temor de su padre durante sus años de cautiverio y cita el testimonio de Francisco Mateu sobre la ejecución de Ángel García (Vázquez, 2005: 240). Sin embargo, la obra dramática se abre, tras la alusión a Ángel García por Pombo, con las voces en español de los asesinos que están dándole un paseo a alguien. Se materializan así en escena las siniestras imágenes que están pasando por la mente de Pombo sentado en su mesa de trabajo, a lo que se añade el chant de mort, en acotación, que reaparece al final de la secuencia 5: "Chant de mort, dar un paseo qui se fait plus intense" (Doutreligne, 2003: 31). Es obvio que la autora ha retenido con fuerza esos asesinatos políticos dándoles un relieve, en proporción, mayor que en la obra original. También hay una amplificación del uso de anglicismos por Ernesto Amescua, a quien su padre envió a estudiar a los EEUU. La novela pone en boca suya, en el curso de sus conversaciones con Pombo, muchos menos anglicismos que la obra dramática, lo que permite a la autora insistir cómicamente en el nuevo carácter made in USA del joven editor".

Dos pasajes de la novela han sido significativamente ampliados por la autora dramática, dando a algunos personajes una presencia relativa mucho mayor de la que tenían en la novela. La idea de una autobiografía imaginaria de Franco le ha sido sugerida al editor por la pregunta de su hijo adolescente: Papa, c'était qui Franco? (Vázquez, 2005: 24; Doutreligne, 2003: 6). La obra dramática añade una secuencia en la que Pombo intenta hablarle a ese adolescente, Juanito, de Franco y su intervención en la historia. En esa escena, amarga y divertida por momentos,

${ }^{9}$ Los feeling y timing de la novela (Vázquez, 2005: 23, 24) se multiplican en la obra dramática en: Okay? All right (Doutreligne, 2003: 88), manage, driver, brainstorming, lunch (13), scoop (53) money (54) What do you mean? Oh man, tu délires ou quoi? (29), etc. 
Pombo intenta captar la atención de un adolescente absorto en su game boy, lleno de autosuficiencia y con escaso interés por la historia. Le suenan algunos nombres pero tiene un escaso conocimiento de las cosas y reacciona más a la idea de los fusilamientos que a otra cosa, lo que nos da una idea del videojuego en que está absorto. Es más, el personaje de Juanito, que representa de algún modo el olvido y la indiferencia de una parte de la juventud por el pasado histórico, permanece en escena durante las dos secuencias siguientes, interactuando incluso con Carmen Polo. Aunque a lo largo de sus apariciones sigue portándose como un adolescente lleno de suficiencia, en ocasiones se muestra sensible a algunas cosas que se cuentan; así ocurre cuando Pombo recuerda la mísera niñez de pastor de su padre o un salvaje regalo de cabezas cortadas de árabes a la duquesa de la Victoria (Doutreligne, 2003: 21, 22). Como si la autora, pese a esa indiferencia de los jóvenes representada por Juanito, insinuara que todo no está perdido y que la responsabilidad de ese olvido recae ante todo en los educadores. Así, es el propio padre de Juanito, el editor Amescua, quien pone al final las actividades extraescolares de su hijo por encima de sus encuentros con Pombo: "Ah, au fait, merci pour mon fils... si, si, ça lui a bien plu... enfin là, il commence les cours de karaté, alors sa mère, tu comprends... mais il va revenir te voir... les femmes, tu sais ce que c'est, Pombo" (Doutreligne, 2003: 40).

La ampliación de la breve alusión del relato al adolescente en varias secuencias dramáticas pone de manifiesto la preocupación de la autora por la memoria histórica, en consonancia con la obra original pero, proporcionalmente, con mayor relieve en la obra teatral. Lo confirma el hecho de que las negociaciones de Pombo con su editor, limitadas en la novela a las páginas iniciales y finales, ocupen cuatro de las once secuencias de la obra teatral, repartidas además a lo largo de la misma. Louise Doutreligne ha insistido en la falsedad del interés del editor por la memoria histórica: su único interés es que Pombo escriba una obra de vulgarización que dé dinero. De ahí que, al final, decida quedarse con el trabajo de Pombo, pero limitándolo a las intervenciones del general, esto es borrando todos los ruidos, como él mismo los llama, con que Pombo contradecía al dictador para que no se olvidaran los padecimientos que infligió a los ciudadanos, antes, durante y después de la Guerra Civil. Como en anteriores ocasiones, la autora ha recogido un elemento esencial de la obra fuente, pero le ha dado una particular insistencia. No solo las negociaciones con el editor ocupan cuatro secuencias de las once de la obra, sino que, dentro de la forzosa reducción de la novela en obra dramática, se han mantenido los personajes secundarios de la secretaria de Amescua, Cristina, y su director literario, Fernando, todos ellos confabulados para que Pombo escriba lo que necesitan de él. El interés exclusivamente comercial por el proyecto hace incluso que el director literario critique la falta de sexo en el trabajo de Pombo y proponga una edición para adultos en la que, aprovechando la afición del dictador por las películas de Sofía Loren, este podría salir masturbándose:

Non, sans blague... on pourrait faire un format adulte, ça ferait un tirage supplémentaire avec je sais pas moi... maintenant les gens y s'en foutent de savoir si Franco a été un salaud ou pas, tu comprends, faut le montrer quoi... en direct... je dirai presque en images, tu vois... je sais pas moi, 
cette histoire avec Sophia Loren, et bien, j'en ferais une scène... oui une scène où il se... il se... manipule, tu vois, en cachette, devant un film de Sophia, ça, je suis sûr que ça se vendrait, ça... (Doutreligne, 2003: 29).

Estas amplificaciones no tienen como objeto proporcionar una información suplementaria al público receptor francés para que entienda la obra. La ausencia de aclaraciones con esa función pone de manifiesto que, para la autora, la figura de Franco es lo suficientemente conocida por el público de lengua francesa como para necesitarlas. Tan solo hemos encontrado dos excepciones. Así, en relación con Serrano Súñer, la obra dramática reproduce el calco de la traducción de cuñadísimo en beau-frérissime (Vázquez, 2005: 102), pero le añade una explicación para quien no estuviera al tanto del origen de ese apelativo: "le beau-frérissime on l'appelait, tant il voulait se hisser au niveau du Généralissime" (Doutreligne, 2003: 19). Paralelamente, el gusto del dictador por la mujer española en la figura de la actriz Juanita Reina (Vázquez, 2005: 299) se ha transformado en interés por Sofía Loren, mucho mejor conocida por los lectores franceses.

En conclusión, la creación dramática de Louise Doutreligne ha reducido pero ha conservado lo esencial de la novela. En ningún caso las supresiones desdibujan la imagen del dictador o de Pombo que da Vázquez Montalbán. Ahora bien, esa reducción no se ha dado siempre con la misma intensidad: no solo algunos fragmentos, a modo de citas, han sido conservados, sino que otros han sido ampliados, en consonancia con las inquietudes de la autora. Esas ampliaciones tienen sus raíces en el texto; han sido un modo personal de insistir, pero de insistir en la misma dirección que la obra fuente. Finalmente, son escasas las sustituciones o aclaraciones, lo cual es indicativo de que se ha pensado que el público francés dispone de suficientes conocimientos sobre el tema y, por lo tanto, no necesita más aclaraciones que el español.

\section{De la temporalidad de la fábula narrativa a la temporalidad de la fábula dramática}

Afirma Genette (1992: 398) que la flexibilidad temporal apenas tiene equivalente en la escena "dont la caractéristique essentielle (la représentation, justement, où tout est par définition au présent), s'accommode mal des retours en arrière et anticipations qu'elle pourrait difficilement affecter des signes du passé ou du futur", por lo que esta recurre a menudo para las analepsis indispensables a procedimientos narrativos. Y efectivamente, las analepsis narrativas, es decir, el relato realizado por algún personaje de hechos acaecidos en un tiempo pasado en relación con el presente de la fábula, son tan frecuentes en la novela como en la obra dramática.

El momento de enunciación de la novela, cuando Pombo escribe la autobiografía imaginaria del dictador, es doble: en el primer capítulo, Pombo habla una vez que ha aceptado el encargo pero todavía no ha empezado a escribir; en el último, lo hace cuando acaba de entregar el manuscrito al editor, el cual lo ha conservado borrando las partes en que la voz de Pombo y otros citados por él contradecían al general. 
Entre ambos capítulos suena la voz imaginaria del dictador, el cual nos indica, de hecho, en qué momento ha redactado esas memorias: se trata de un proyecto iniciado hace años, pues afirma guardar el secreto "de cette autobiographie, sur laquelle je m'escrimais depuis des années déjà" (Vázquez, 2005: 526), de lo que se deduce que el punto de enunciación intradiegético es móvil y se desplaza imperceptiblemente hasta los últimos momentos del dictador, cuando dirige su obra a la juventud española, "anxieux qu'une fausse image de moi vous soit un jour présentée, qui serait donc une fausse image de notre pays" (2005: 527). El general relata, pues, en la novela sus años pasados con continuas analepsis, a la que responde Pombo con las suyas, ya sea recurriendo a su propia historia y la de su familia o a testimonios de terceros sobre el pasado del dictador, que desmontan la propia versión de este. Esas analepsis narrativas son también muy frecuentes en la obra dramática, aunque no tienen una correspondencia exacta con las de la novela: Pombo, Franco, Carmen Polo e incluso Ernesto Amescua recuerdan en sus conversaciones hechos del pasado, ya sea del ámbito del dictador, ya sea del ámbito de Pombo, recurriendo también a veces a testimonios de terceros. Así, a modo de ejemplo, Pombo en la obra dramática contradice la imagen que da el dictador de su época colonial leyéndole a Juanito buena parte del texto del general republicano Hidalgo de Cisneros recogido por la novela (Vázquez, 2005: 139; Doutreligne: 2003: 17).

Sin embargo la fábula dramática de Louise Doutreligne tiene una flexibilidad temporal equivalente e incluso superior a la de la novela. Esa flexibilidad temporal es una construcción dramática en respuesta a la constante acronía que se produce en la novela por el hecho de que la voz intradiegética del dictador muerto suene junto a la voz extradiegética de Pombo, que no deja de interpelarlo y contradecirlo desde su presente, aunque sin respuesta alguna por parte de aquel. Louise Doutreligne ha transmodalizado esa acronía haciendo que en la escena se representen, ya sea por los mismos o por otros personajes, hechos con una simultaneidad o una sucesión que no se corresponden con la realidad. En otras palabras, las analepsis, e incluso algunas prolepsis desde analepsis, son escénicas. El espacio escénico, único en la realidad del escenario, adquiere así una extraña plasticidad: acoge espacios-tiempo diferentes, cada uno de ellos con sus propios personajes, a veces compartidos, con la posibilidad de confluencias, imposibles en la realidad, cuando esos personajes interactúan desde espacios-tiempo diferentes.

La primera secuencia nos ilustra este fenómeno. Pombo está sentado en su mesa de trabajo; ha comenzado, pues, la escritura pero no consigue hacer hablar al dictador, para lo que necesita el imaginario permiso de su padre muerto. Previamente, de hecho, han sonado unas voces relacionadas con el asesinado de Ángel García, un episodio al que se alude mucho más tarde en la novela, pero que pertenece al pasado (Vázquez, 2005: 240). A continuación, en la misma escena, Pombo se traslada al pasado reciente, interactuando con el editor Amescua en las negociaciones previas a su aceptación del proyecto. Y esto no es todo: a mitad de la escena, la entrada del editor literario Fernando criticando la pesadez del trabajo de Pombo constituye una prolepsis que nos adelanta al momento, futuro en relación 
con el comienzo de la obra, en que Pombo ya ha concluido al menos buena parte de su libro (Doutreligne, 2003: 10), todo ello para volver al momento inicial en que Pombo se dirige otra vez a su padre ausente, mientras suena la seductora oferta económica del editor en el pasado reciente. La voz de Pombo, pues, sin solución de continuidad, ha hablado desde diferentes momentos de la historia y, paralelamente, ha hecho que el espacio escénico, sin que conste ni siquiera una acotación al respecto, pase de representar su despacho a representar el de la editorial y, para terminar, otra vez su propio despacho. El hecho de que suenen al principio las voces de los asesinos que le están dando a alguien el paseo o, al final, la de Amescua en off, recordando a Pombo el dinero prometido -"Douze mille euros sur les droits d'auteur (...) C'est pas la garantie d'une collaboration, ça?" (Doutreligne, 2003: 12)-, aumenta la flexibilidad temporal y espacial de la escena, haciendo que otros tiempos y espacios confluyan sin la presencia física de sus personajes, solo la de sus voces.

Esas acronías dramáticas se mantienen durante toda la obra haciendo que coincidan en escena Pombo y Juanito - personajes situados pues en el presente postfranquista en que Pombo escribe- con un Franco anciano y enfermo, ya fallecido en el presente de los otros personajes, y su esposa Carmen. Se produce así otra vez una confluencia de espacios de ficción dramática en la escena, sin que haya siempre acotaciones claras, aunque los objetos nombrados en ellas son a veces alusivos: Pombo en su despacho -"Pombo, à son bureau, prêt à intervenir", cuando aparece por primera vez el dictador (Doutreligne, 2003: 33)-, Pombo y Juanito seguramente en la habitación del niño -"Pombo avec Juanito jouant à la gameboy" (Doutreligne, 2003: 15)-, Franco y Carmen en un lugar íntimo que podría ser su domicilio o una habitación privada de hospital : "Franco, en peignoir de soie et caleçon de soie, accompagné par Carmen son épouse, son garde du corps Paco et son médecin particulier" (Doutreligne, 2003: 33), "Pombo regarde le Général déguster son yaourt" (Doutreligne, 2003: 41), "Carmen au loin regarde un poste de télévision portable" (Doutreligne, 2003 45). Tratándose de espacios y tiempos separados en la realidad, la escasa interacción que hay entre Pombo y Juanito, por un lado, y Franco y su esposa, por el otro, es meramente escénica e imaginaria.

Las rupturas del transcurso de la ficción dramática son otra prueba de su flexibilidad temporal. El transcurso de la obra se asocia con la progresiva escritura del encargo que ha aceptado Pombo. Esa escritura se dramatiza por medio de las voces que en ella intervienen, convertidas en personajes: la extradiegética de Pombo, las intradiegética del dictador y de Carmen. La obra dramática, de hecho, comienza cuando Pombo está a punto de empezar a escribir y concluye cuando ha entregado su trabajo al editor, por lo que, en primera instancia, todo lo que ha ocurrido en escena entre ambos puntos, incluso las conversaciones con el editor y su hijo Juanito, remite al transcurso en el tiempo de la composición de la autobiografía. Las intervenciones de Franco y Carmen desestabilizan el transcurso del tiempo dramático: son analepsis en relación con el momento en que Pombo escribe y también, secundariamente, en relación con el momento del pasado en que hablan esos personajes, pues se refieren a menudo a hechos anteriores; así, Franco, 
ya fallecido, habla - primera analepsis en relación con la escritura de Pombo- de cosas que le ocurrieron desde su juventud -segunda analepsis, esta vez en relación con el momento en que el propio Franco habla. Ahora bien, esas analepsis, se desarrollan y suceden entre ellas hacia adelante en el tiempo, acercándose pues al momento de escritura de Pombo, ya que los recuerdos de Franco y de Carmen rememoran la historia del caudillo desde el pasado hasta el momento presente en que, anciano y decrépito, Franco toma la palabra. Lógicamente, esas analepsis no alcanzan el momento en que Pombo escribe ya que, cuando lo hace, el dictador ha muerto. Por el contrario, las intervenciones del editor, que no son propiamente analepsis en relación con la escritura de Pombo, ya que corresponden a contactos con el escritor mientras escribe, no solo alcanzan esa escritura sino que van más allá de su final. Lo ponen de manifiesto las dos últimas secuencias de la obra: en la penúltima Pombo ya ha entregado su texto al editor y en la última Pombo se dirige imaginariamente a su padre tras haber cobrado cuatro millones de pesetas por su trabajo.

Así pues, la flexibilidad temporal de la obra dramática se concentra en dos fenómenos. Por una parte, coexisten en la escena espacios-tiempo diferentes, cada uno con sus propios personajes. Por otra, el transcurso dramatizado de la escritura de Pombo sufre constantes analepsis cuando intervienen personajes en momentos anteriores al de la escritura, aunque esas analepsis se sucedan también hacia delante, en el mismo sentido que transcurre la escritura de Pombo. A ello hay que añadir otro fenómeno que estudiaremos en la polifonía, por estar vinculado a esta: personajes situados en espacios-tiempo separados de la ficción dramática a veces interactúan, lo cual provoca su enigmático encuentro en la escena.

La afirmación de Genette con que comenzábamos este apartado (1992: 398) no parece aplicarse a esta obra dramática: la flexibilidad temporal de la novela ha sido ampliamente recogida en ella. La mera lectura del texto dramático pone de manifiesto sus continuas acronías, apoyadas a veces, como hemos visto, en unas discretas acotaciones, referidas más a los objetos alusivos a espacios que a los espacios mismos. Esas escasas acotaciones de tiempo y lugar, unidas a las acronías del texto, dejan en manos del director teatral la posibilidad de incorporar en la puesta en escena señales de los cambios de espacio y de tiempo. Unas señales que, si son fieles al texto, deberían sugerir los diferentes momentos y lugares en que hablan e intervienen los personajes, pero también su pertenencia a un mismo ámbito, por lo que serían preferibles las transiciones a los cambios bruscos. Y es que, a fin de cuentas, todo pertenece a un mismo espacio y tiempo: el de la escritura de Pombo.

\section{De la polifonía narrativa a la polifonía dramática}

Dentro de la transmodalización, nos ha llamado la atención el paso de la polifonía del relato a polifonía dramática. La autora ha derrochado creatividad dando una respuesta teatral a la polifonía narrativa, añadiendo incluso aportaciones suyas. En 
el relato, la voz extradiegética de Pombo introduce la voz intradiegética del dictador; la primera se sitúa en el universo marco de la ficción -el espacio-tiempo en que Pombo escribe-, la segunda en el universo enmarcado de la ficción -el espaciotiempo en que el general habla. Entre ambas voces hay una extraña relación: la voz intradiegética de Franco no es sino la propia voz de Pombo disfrazada ya que, aun cuando este consiga imitar al general, él es quien habla en definitiva. Muy pronto en el relato, las voces se alternan, pues Pombo no puede evitar replicar al general contradiciendo sus aseveraciones, ya sea con sus propias palabras, ya sea citando otros testimonios. Sin embargo, esas dos voces no dan señales de interactuar en ningún momento, pues nada hay que dé a entender que el dictador escucha las críticas que se le hacen. Esta polifonía ha recibido un tratamiento muy particular en la obra dramática, ya sea mediante la materialización de voces en personajes, ya sea mediante la relación que se establece entre ellos.

En la novela, Pombo habla de personajes de su mismo universo de ficción, el universo marco, citando a veces sus palabras: Amescua y Juanito, principalmente. También hace hablar a Franco, personaje central del universo de ficción enmarcado, el cual alude a su vez a otros personajes, como lo hace también Pombo. Las voces intradiegética de Pombo y extradiegética del general se han querido diferenciar en el relato hasta tal punto que en las ediciones que hemos consultado, las del texto original y de su traducción, las palabras de Franco figuran en letra cursiva. En la creación dramática, Pombo se convierte en personaje del mismo modo que otras voces, ya pertenezcan a su mismo universo marco de ficción -Juanito, Amescua, el equipo del editor-, o al enmarcado -Franco y su esposa Carmen.

Carmen, de hecho, está más presente en la creación dramática que en la novela. El dictador alude en varias ocasiones a ella en el relato, pero Louise Doutreligne la ha convertido en un personaje situado al mismo nivel que él. Es más, corroborando lo difícil que le resulta a Pombo hacer hablar al dictador, aparece en escena antes que este, cosa insólita en relación con la novela, donde la voz del General fluye sin ningún problema tras el capítulo introductorio. También es significativo que varias intervenciones realizadas por el dictador en la novela hayan sido atribuidas a Carmen o a ambos a la vez, con la esposa apostillando constantemente el discurso de su marido:

J'aime me consacrer à de petits bricolages qui tapent un peu sur les nerfs de Carmen: par exemple, j'ai retiré la tulipe de verre qui couvrait l'ampoule du miroir de la salle de bains parce qu'elle tamisait trop la lumière et que je ne pouvais pas me tailler correctement la moustache (Vázquez, 2005: 385).

CARMEN: Il aimait se consacrer à de petits bricolages qui me tapaient un peu sur les nerfs mais enfin... Par exemple, il avait retiré la tulipe de verre qui couvrait l'ampoule du miroir de la salle de bains parce qu'elle tamisait trop la lumière et qu'il ne pouvait pas se tailler correctement la moustache (Doutreligne, 2003: 27).

Las apostillas de Carmen, al tiempo que muestran una dependencia del dictador con ella, lo cual contrasta con el aura de omnipotencia que lo envuelve, pueden servir para ridiculizarlo, desacreditando sus propias palabras: 
FRANCO: Mais enfin, moi, on m'a bien fusillé des intellectuels aussi remarquables que... Que...

CARMEN: Que, que... je sais pas moi $^{10} !(2003: 34)$

Que Franco y su esposa interactúen entre ellos, no es sorprendente, ya que ambos pertenecen al mismo universo enmarcado de ficción. Lo sorprendente de la obra dramática es cómo diferentes voces de la polifonía, encarnadas en personajes pertenecientes a espacios-tiempo separados, tienen contacto entre sí, algo a todas luces imposible que se produzca en la realidad. El primer contacto de estas características se produce en la secuencia 3. Carmen aparece en escena, viuda, cubierta de joyas y arrastrando un gran retrato de Franco. Durante la mayor parte de la secuencia habla del dictador, refiriéndose a sus primeros tiempos, ante Juanito y Pombo, situados en otro universo de ficción. Pese a ello, estos reaccionan a veces a las palabras de Carmen, como si esta estuviera realmente presente. En unos casos son breves reacciones de risa -“JUANITO (rit): Ah, Paquito!" (Doutreligne, 2003: 19), sorpresa -“POMBO et JUANITO: "Un berbère!” (Doutreligne, 2003: 19) o indignación -“JUANITO: La vache!!” (Doutreligne, 2003: 29)-, hasta que Pombo replica a Carmen hablándole de la miseria de su familia en los tiempos pasados. Carmen, que hasta ahora no ha reaccionado en ningún momento a las palabras de Juanito y Pombo, lo hace entonces, aunque por poco tiempo ya que, al instante, sigue con su propio discurso, haciendo oídos sordos a los demás:

CARMEN: En tout état de cause, à sa mort, Franco a forcé le retour de son père au sein de l'Église comme il a forcé l'Espagne à revenir à son essence catholique.

POMBO: Moi je n'ai forcé mon père ni à partir ni à revenir, mais lors de vos flâneries au port de La Coruña, vos yeux se sont-ils arrêtés une fois sur le paquebot Alfonso XII.

CARMEN: Alfonso XII?... non, je ne vois pas... non... (Doutreligne, 2003: 20).

La secuencia 4 reproduce estos comportamientos, añadiendo algunos toques. Carmen sigue hablando de Franco, reaccionado puntualmente y de modo evasivo a las palabras de Pombo, como cuando, por ejemplo, este alude a la Pasionaria (Doutreligne, 2003: 25), mientras Juanito, enfrascado en su game boy, hace de vez en cuando algunas preguntas sin interés a lo que oye. Sin embargo, la interacción entre los personajes llega aquí más lejos que en la escena anterior: pasa de las palabras a los gestos cuando Juanito, que está oyendo a Carmen cantar zarzuela, le saca una tarjeta roja (Doutreligne, 2003: 27); además, la propia Carmen se irrita al darse cuenta de que Pombo, sumido en sus pensamientos, no le está haciendo caso:

${ }^{10}$ Estas palabras de Carmen son una aportación de la autora dramática, que permiten un sutil gag, haciendo que suene "je sais pas moi" como un nombre español deformado por la fonética francesa. Así lo hizo la actriz que tuvo el papel de Carmen en la puesta en escena de Jean-Luc Paliès, Théâtre de Saint-Maur (2009). 
CARMEN: $[\ldots]$ mais... vous ne m'écoutez pas?

POMBO: Non je rêve, Señora Franco, je rêve au petit palais, aux quinze mille hectares, au fortin familial... et je m'interroge... où partait l'argent espagnol pendant les années quarante et cinquante... à Cuba?

Así pues, en la ficción dramática como en la novela, la voz extradiegética escucha y replica a la voz intradiegética; ahora bien, en la obra dramática la voz intradiegética no consigue siempre escapar a las preguntas de Pombo, ya que reacciona, aunque sea de modo puntual y sin sentirse realmente aludida, e incluso llega a preocuparse de que no la escuchen como se merece.

El tratamiento de la polifonía es similar en las secuencias en que aparece Franco, la 6,7 y 8 . A lo largo de esas secuencias, Franco, presentado como un anciano enfermo y decrépito, hace el elogio de su propia obra, convencido de su grandeza, con las continuas apostillas de su esposa Carmen. Pombo, presente en las tres secuencias, lo escucha y no puede evitar replicarle con vehemencia, contradiciéndolo y contando la historia de represalias vivida por su familia. El dictador sigue con su propio discurso sin contestar en ningún momento. La polifonía dramática reproduce pues, así, lo esencial de la narrativa: discurso autista de Franco, escucha y réplicas de Pombo sin respuesta. Sin embargo, en la obra dramática hay unas sutiles diferencias. En primer lugar, están las continuas apostillas de Carmen, que llegan a convertirse en un eco que repite o insiste machaconamente sobre lo que dice el dictador, ridiculizándolo indirectamente. En algunos casos, Pombo también repite algunas palabras del dictador; no hay acotaciones al respecto, pero suponemos que lo hace en un tono irónico o de incredulidad:

FRANCO: "Mais à quelque chose malheur est bon".

POMBO: "À quelque chose malheur est bon"!

FRANCO: C'est la phrase de ma pauvre maman qui m'est venue quand j'ai présenté mes condoléances à sa veuve...

CARMEN: "À quelque chose malheur est bon!", ce mot d'ordre de toute son existence... (Doutreligne, 2003: 48).

Por otra parte, no hay interacción directa con Franco, pero sí la hay indirectamente, en algún momento, a través de Carmen. Así, refiriéndose a la ejecución de Julián Grimau, se produce un breve intercambio de palabras entre Carmen y Pombo

POMBO: (...) Il a été exécuté pendant la Semaine Sainte...non?

CARMEN: C'est possible... mais le peuple savait bien qu'au moment où l'on a pris son sort entre nos mains il allait en espadrilles, et vingt ans après en Seat 600!

POMBO: Pas pour tout le monde la Seat! (Doutreligne, 2003: 47).

Además, dentro de lo escasas que son las acotaciones, hay una que invita a una puesta en escena en que Franco y Pombo, pese a no hablarse recíprocamente, interactúen con gestos. Así, la secuencia 8 hace preceder las palabras de Franco, de la siguiente indicación: "Franco s'approche de façon quotidienne de Pombo. (...) 
en confidence" (Doutreligne, 2003: 45). Sin embargo, hay una razón de peso para que Pombo, contrariamente a como lo hace con Carmen, no interactúe con Franco; de hecho, sus réplicas suelen ser largas y claramente diferenciadas de las palabras del dictador. Y es que Pombo y Franco son, a fin de cuentas, una misma voz, ya que el primero simula la del segundo. Cabe pues la posibilidad de un juego escénico en que un mismo actor se transforme de Pombo en Franco y viceversa, haciendo así visible que las voces intradiegética y extradiegética son, en realidad, de un único personaje ${ }^{11}$.

En resumen, la polifonía de la novela, que jerarquiza las voces según pertenezcan al universo marco o al universo enmarcado de la ficción, se convierte, a su paso a la obra de teatro, en polifonía de voces que comparten un mismo espacio escénico, ya sean extradiegética o intradiegéticas, al tiempo que se materializan en personajes. Algunas de esas voces tienen mayor presencia en la creación dramática. Es el caso de la de Carmen: en la novela se alude a ella, pero nunca interviene al mismo nivel que Franco; en cambio, en la creación dramática es una voz más, junto a la de Pombo y Franco, que retoma parte del discurso del dictador, a quien constantemente apostilla. Finalmente, en la novela Pombo escucha a Franco y le replica sin que este conteste: no hay pues cooperación comunicativa entre la voz extradiegética y la voz intradiegética. Por el contrario, en la creación dramática sí hay una mínima interacción entre Pombo, Juanito y Carmen, aunque la esposa del dictador haga finalmente poco caso a lo que le dicen. Se pone así de manifiesto algo propio de las dictaduras: les gusta ser escuchadas pero no tanto escuchar.

\section{Conclusión: liberarse para no olvidar}

La dramatización de Louise Doutreligne tiene la particularidad de ser original y, al mismo tiempo, fiel a la novela de Vázquez Montalbán. Los cambios introducidos, como necesaria consecuencia de una transmodalización cuantitativamente reductora, no alteran lo esencial de la obra fuente. Es más, respetan en ocasiones el texto original hasta tal punto que parecen citarlo invitándonos a su lectura desde la obra dramática. La creatividad de la autora le ha permitido encontrar equivalentes dramáticos a elementos fundamentales del universo de ficción del relato como su acronía y su polifonía. Y, salvo casos excepcionales, como es la sustitución de Juanita Reina por Sofía Loren en la afición cinéfila del dictador, no ha habido cambios o aclaraciones en vistas a una recepción por un público no español, admitiéndose implícitamente que este dispone de suficientes elementos para entender la obra. Ahora bien, Louise Doutreligne ha acentuado aspectos de la obra original en función de sus preocupaciones personales. Así, la importancia que

\footnotetext{
${ }^{11}$ Así lo entendió Jean-Luc Paliès, director y actor de la obra, con el doble papel de Pombo y Franco, en su puesta en escena estrenada en el Théâtre de Saint-Maur (2009).
} 
adquieren, en proporción con la general reducción del hipotexto, el personaje de Juanito y las negociaciones con los editores, revela su preocupación por que la transición democrática española suponga el olvido de los crímenes del franquismo. Louise Doutreligne, de hecho, entrevistada por Irene Sadowska, exponía su interés, en la historia reciente de España, por "el paso del poder, del franquismo a la democracia, sin violencia, con una cierta continuidad", así como por "la lucha ética y política que vivo todos los días como autor" (2003: 73), reflejada en los problemas de conciencia que le supone a Pombo, antifranquista hijo de antifranquista represaliado, aceptar el encargo de una autobiografía imaginaria del dictador. La autora también mostraba en esa entrevista su cuestionamiento de las contradicciones entre el olvido y la memoria, consciente de que ambas son necesarias: "necesitamos a la memoria para poder olvidar, para hacer duelo del pasado. No podemos permanecer en el pasado constantemente, si no ya no avanzamos" (2003: 74).

Ciertamente, no hemos estudiado en este trabajo todos los aspectos de esta transmodalización. No hemos investigado, en concreto, la transformación de parte de la narración en acotaciones así como la importancia concedida a los elementos visuales y musicales. Las acotaciones funcionan a menudo como reducciones del texto fuente con vistas a una recepción sintética, que une las palabras de los personajes a la puesta en escena, de lo que en la novela forzosamente da lugar a una percepción analítica. Así, a modo de ejemplo, la insistencia de Pombo en la novela sobre la decrepitud final de dictador queda recogida en las acotaciones como: "Carmen fait un signe au médecin pourqu'il lui donne des pilules" (Doutreligne, 2003: 34). Las acotaciones también nos indican un uso de la iconografía oficialista de Franco que permite reducir las descripciones del dictador en la novela; así, al comienzo de la tercera secuencia, Carmen Polo entra en escena arrastrando un gran cuadro del dictador (Doutreligne, 2003: 19) y en la cuarta presenta su colección de retratos del mismo (Doutreligne, 2003: 25). Las acotaciones musicales son asimismo frecuentes y contribuyen a reforzar el clima emocional de la obra ahorrando texto: chant de mort ligado a la imaginación de los paseos (Doutreligne, 2003: 5, 14, 28), una canción de La Habana ligada a los recuerdos del padre de Pombo (Doutreligne, 2003: 23), una litanie profonde simultánea al recuerdo de su mísera infancia (Doutreligne, 2003: 21). Sirvan estos ejemplos para mostrar que no hemos agotado este tema de investigación y la necesidad de tener en cuenta las puestas en escena de la obra, ya que la parquedad de las acotaciones del texto puede ser estímulo de creatividad para el director teatral.

Hay varias formas de combatir intelectualmente las dictaduras. Louise ha recogido en su obra dramática la visión crítica de la historia del franquismo y de nuestra relativa desmemoria actual que hay en la novela. Pero también ha puesto al dictador ante nuestros ojos en la escena; y ahí, no ha podido evitar jugársela con su talento creativo y transgresor. El dictador, envuelto en el aura de su misión histórica, cultiva una distancia con el común de los mortales, ante los que se justifica repitiendo machaconamente unos argumentos que no convencen a nadie. Pero Louise Doutreligne, por así decir, nos lo pone a mano, mostrándolo como un 
anciano decrépito, en paños menores, constantemente apostillado por su esposa. Y de este modo, pese a la amargura destilada, hasta nos hace reír de él. Y, con esa risa, nos liberamos. Una risa luminosa no para olvidar lo sucedido, sí para transformar los sentimientos que dejaron las heridas del pasado en fuerzas positivas.

El librement inspiré du roman de Manuel Vázquez Montalbán, que acompaña al título, da cuenta de la libertad con que la autora dramática ha procedido a esta transmodalización, una libertad cimentada en una visión crítica del dictador, compartida con el novelista. No ha manejado un criterio regular en las transformaciones cuantitativas, dejándose guiar seguramente por su intuición, y ha optado por mantener aspectos del universo narrativo origen que, por las intrínsecas características del género dramático, no se pueden trasladar llanamente, como son las acronías y la polifonía. Ciertamente, si Louise Doutreligne hubiera optado por transformar la novela en un monólogo dramático en que únicamente Pombo hablara, aun citando otros personajes, la obra teatral estaría, al menos formalmente, más cerca de la novela. Librement inspiré remite también a una libre elección de coordenadas dramáticas que, como en este caso, obligan a una transmodalización, por así decir, oblicua. Esa libertad creativa es también la que ha llevado a la autora a dar un desarrollo mayor, en proporción, a aspectos de la obra origen, por sus propias inquietudes, como son la memoria histórica o los problemas de conciencia del escritor. Y finalmente, la autora también se ha sentido libre para ridiculizar a veces por medio del juego escénico al dictador, en consonancia con el modo en que él mismo se ridiculiza por sus palabras tanto en la novela como en la obra dramática.

\section{REFERENCIAS BIBLIOGRÁFICAS}

Doutreligne, L., (2003) Signé Pombo. París, Éditions de l'Amandier.

Genette, G., (1992 [1982]) Palimpsestes. París, Éditions du Seuil.

Keller-Rahbé, E., (2012) "Romans du XVII ${ }^{\mathrm{e}}$ sur la scène contemporaine" in Douzou, C. \& F. Greiner (eds), Le roman mis en scène. París, Classiques Garnier, pp. 233-246.

Martín Bermúdez, S., (2003) "Firmado Pombo" Trad. española de Doutreligne, L., (2003) Signé Pombo. París, Éditions de l'Amandier, in Primer acto: Cuadernos de investigación teatral. $\mathrm{N}^{\circ}$ 298, pp. 81-107.

Miñano, E., (2009) "La recepción interna en tres Séductions espagnoles de Louise Doutreligne: Don Juan d'origine, Faust espagnol y Carmen la nouvelle" in Quaderns de Filologia. Estudis Literaris. No XV, pp. 132-156.

Miñano, E., (2010a) "Les Séductions espagnoles de Louise Doutreligne" in La culture de l'autre: l'enseignement des langues à l'Université, Encuentro Hispano-Francés de investigadores (APFUE - SHF). Lyon, ENS LYON/DGESCO, disponible en : http://cle.ens-lyon.fr/espagnol/les-seductionsespagnoles-de-louise-doutreligne 92799.kjsp [Último acceso el 12 de julio de 2013].

Miñano, E., (2010b) "Lecture et écriture dans l'univers dramatique de Louise Doutreligne" in Çédille. $\mathrm{N}^{\mathrm{o}}$ 6, pp. 164-201. 
Moss, J., (1987) "Women's Theatre in France" in Signs. Vol. 12, no 3, pp. 549-567. Sadowska, I., (1997) "La irresistible ascensión y conquista de la legitimidad" in Gallaire, F. (et al.), Dramaturgas francesas contemporáneas. Universitat de València, pp. 9-30.

Sadowska, I. (2003) "El boomerang de la memoria. Entrevista con Louise Doutreligne" in Primer acto: Cuadernos de investigación teatral. № 298, pp. 72-78.

Doležel, L. (1986) "Semiotics of the Literary Communication" in Strumenti Critici. Nueva serie, $\mathrm{n}^{\circ} 1$, pp. 5-48.

Vázquez, M. (2005 [1982]) Autobiografía del general Franco. Barcelona, Debolsillo. 